\title{
IMPACT OF A FREEWAY ON THE DISPERSAL OF TICKS AND IXODES RICINUS-BORNE PATHOGENS: FORESTED RESTING AREAS MAY BECOME LYME DISEASE HOTSPOTS
}

\author{
Sándor HORNOK ${ }^{1 *}$, Maria MULVIHILL ${ }^{1}$, Krisztina SzÖKE $^{1}$, Enikő GÖNCZI ${ }^{3}$, \\ Kinga M. SULYOK ${ }^{2}$, Miklós GYURANECZ ${ }^{2}$ and Regina HofMANN-LEHMANN ${ }^{3}$ \\ ${ }^{1}$ Department of Parasitology and Zoology, University of Veterinary Medicine, István u. 2, \\ H-1078 Budapest, Hungary; ${ }^{2}$ Institute for Veterinary Medical Research, Centre for \\ Agricultural Research, Hungarian Academy of Sciences, Budapest, Hungary; ${ }^{3} \mathrm{Clinical}$ \\ Laboratory and Center for Clinical Studies, Vetsuisse Faculty, University of Zurich, Zurich, \\ Switzerland
}

(Received 30 January 2017; accepted 4 April 2017)

\begin{abstract}
Man-made barriers are well known for their effects on ecosystems. Habitat fragmentation, for instance, is a recognised consequence of modern-day infrastructure. The aim of the present study was to investigate the diversity and abundance of tick species, as well as the risks of acquiring tick-borne infections in habitats adjacent to a freeway. Therefore, ixodid ticks were collected from the vegetation at two-week intervals (in the main tick season, from March to June) in eight habitats of different types (forest, grove, grassland) along both sides of a freeway. Ixodes ricinus females were molecularly screened for three species of tick-borne bacteria. In the study period, 887 ixodid ticks were collected. These included 704 I. ricinus (79.4\%), 51 Dermacentor reticulatus (5.7\%), 78 D. marginatus (8.8\%), 35 Haemaphysalis inermis (3.9\%) and 19 H. concinna $(2.1 \%)$. There was no significant difference in the abundance of tick species between similar habitats separated by the freeway, except for the absence of Dermacentor spp. on one side. In I. ricinus females, the overall prevalence of Anaplasma phagocytophilum was low, and (in part due to this low rate) did not show significant difference between the two sides of the freeway. Rickettsia helvetica had significantly different overall prevalence between two distant habitats along the same side of the freeway $(12.3 \%$ vs. $31.4 \%)$, but not between habitats on the opposite sides. Borrelia burgdorferi s.l. showed significantly different overall prevalence between habitats both on the same and on the opposite sides of the freeway (8.6$35.9 \%$ ), and the difference was higher if relevant habitats were also separated by the freeway. Importantly, the prevalence rate of the Lyme disease agent was highest in a forested resting area of the freeway, and was significantly inversely proportional to the prevalence of $A$. phagocytophilum (taking into account all evaluated habitats), apparently related to deer population density. Prevalence rates of
\end{abstract}

*Corresponding author; E-mail: Hornok.Sandor@univet.hu; Phone: 0036 (1) 478-4187

This is an open-access article distributed under the terms of the Creative Commons Attribution License, which permits unrestricted use, distribution, and reproduction in any medium for non-commercial purposes, provided the original author and source are credited. 
these bacteria also differed significantly on single sampling occasions between: (1) closely situated habitats of different types; (2) distant and either similar or different habitat types; and (3) habitats on the opposite sides of the freeway. In conclusion, the findings of the present study show that a fenced freeway may contribute to differences in tick species diversity and tick-borne pathogen prevalence along its two sides, and this effect is most likely a consequence of its barrier role preventing deer movements.

Key words: Hard ticks, Ixodes ricinus, barrier, Anaplasma phagocytophilum, Rickettsia helvetica, Borrelia burgdorferi s.l.

Man-made barriers are well known for their effects on ecosystems. Habitat fragmentation due to roads and traffic, for instance, is a recognised consequence of modern-day infrastructure. In these scenarios mammals and birds are frequently studied (Spellerberg, 1998), but their role as hosts of ixodid ticks is seldom considered.

Host species play an important role in the dispersal, establishment and maintenance of ticks, as well as in the transmission of tick-borne pathogens, their emergence in new regions, and identification of risk areas (Trout Fryxell et al., 2015). Thus, it can be postulated that if tick hosts are restricted in their movements and natural tick habitats become fragmented due to man-made barriers, this will influence the local eco-epidemiology of tick-borne infections.

In Europe several important tick species (e.g. Dermacentor spp.) have medium- to large-size mammals as reproductive hosts on which the adult stages feed/mate (Nosek, 1972), and which consequently are indispensable for perpetuating the tick life cycle (Levi et al., 2012). Large cervids are also important as reservoirs of certain tick-borne bacteria (exemplified by Anaplasma phagocytophilum: Stuen et al., 2013), and therefore their presence has a significant impact on the local epidemiology of relevant diseases. At the same time, large mammals, such as wild living ungulates and carnivores that regularly move over large distances, appear to be the most threatened when roads and human development extend into their natural habitats (Ng et al., 2004). For instance, when geographical clustering of tick-borne encephalitis virus variants was observed, it was partly attributed to man-made barriers that prevent the migration of relevant hosts (Fajs et al., 2012).

In the above context, to the best of the authors' knowledge, no studies evaluating the potential role of freeways in the eco-epidemiology of tick-borne diseases have been reported. Therefore, the aim of the present work (as a pilot study) was to investigate the diversity and abundance of tick species, as well as the risks of acquiring three species of Ixodes ricinus-borne bacteria, in habitats adjacent to a freeway. These target pathogens were chosen on account of their zoonotic significance, and also because the movements/distribution of their main reservoirs (A. phagocytophilum: deer; Borrelia burgdorferi: rodents; $R$. helvetica: ticks) were hypothesised to be influenced differently by a freeway. 


\section{Materials and methods}

\section{Sample collection and habitat characteristics}

Ixodid ticks were collected with the dragging-flagging method in eight individual (numbered) habitats of three different types (Fig. 1) along the two sides of a freeway (close to Gödöllö, coordinates: $47.6213163 \mathrm{~N}, 19.3855835 \mathrm{E}$ ). Habitat types included: (a) 'deciduous forests' (mainly native oak trees, but also planted Robinia) with dense green lower vegetation; (b) 'groves' with sporadic trees and bushes; as well as (c) 'grassland' with scattered shrubs. These habitat types and the sampling period were chosen on the basis of known biotope preferences and seasonal activities of the most important ixodid tick species in Hungary (Hornok, 2009; Hornok and Farkas, 2009). The following eight individual (numbered) habitats, belonging to one of the above three types, were evaluated: three (habitat-1, -4, -8) 'deciduous forests', three (habitat-2, -5, -6) 'groves' and two (habitat-3, -7) 'grasslands' (Fig. 1).

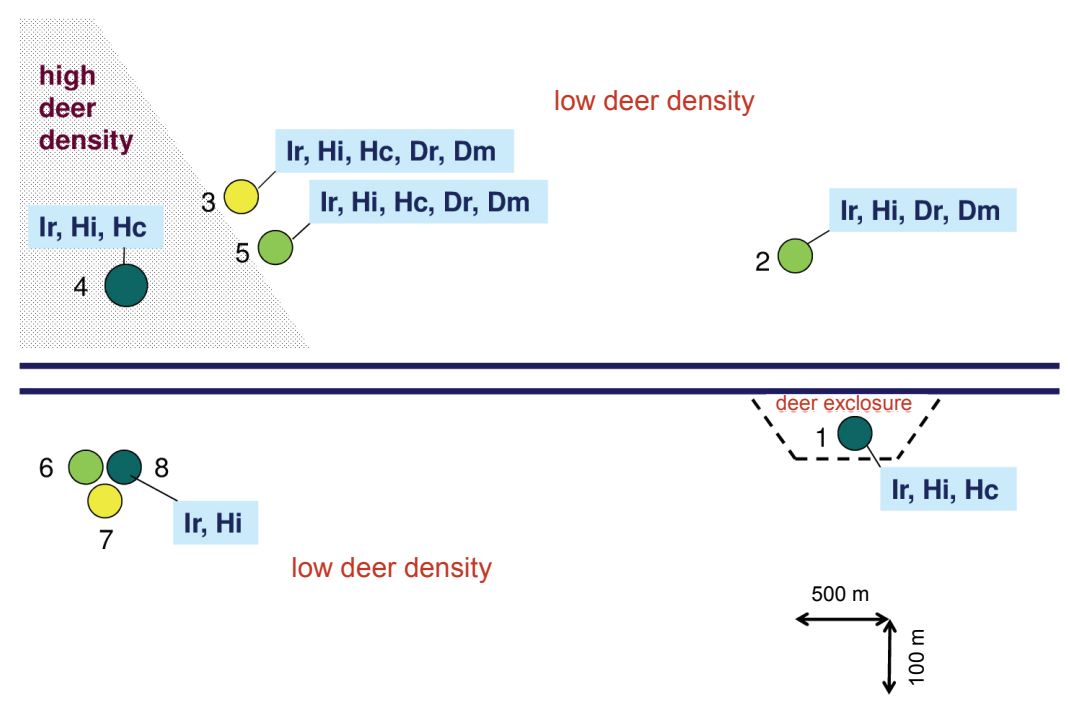

Fig. 1. Schematic arrangement of the eight numbered habitats (sampling sites shown as circles) along the freeway (horizontal double blue line), which runs in east-west direction. The colour inside the circles corresponds to habitat type (dark green: forest, light green: grove, yellow: grassland).

Abbreviated names of tick species that were collected in a habitat (Ir: Ixodes ricinus, Hi: Haemaphysalis inermis, Hc: H. concinna, Dr: Dermacentor reticulatus, Dm: D. marginatus) are connected to its circle

In these eight numbered habitats ticks were collected on six occasions, at two-week intervals (from the second half of March to the first half of June, 2016). These collections were standardised by using $1 \times 1 \mathrm{~m}$ drag cloth, which was drawn along 5 transects of approx. $100 \mathrm{~m}$ length and ticks were removed 
approx. every 20 seconds. Temperature and humidity were measured on selected occasions to exclude major climatic differences between the same habitat types. Ticks were stored in $70 \%$ ethanol until identification of their species according to Babos (1965).

In habitat-4 (Fig. 1), which is a forested hunting area, the main large game animals are red deer (Cervus elaphus) and wild boars (Sus scrofa) (Szemethy et al., 1996), but horses and hunting dogs are also kept within this area. In this habitat red deer density is known to be high due to the connection with populations in the northern mountains of Hungary (Szemethy et al., 1996), and also because game animals regularly receive supplemental food, which results in small home range size and high deer densities around feeding sites (Jerina, 2012). In this hunting area red deer were reported to concentrate and have short distance movements (Szemethy et al., 1995, 1996); their migration to the south (i.e. towards habitats No. 6 to 8 ) is prevented by freeway fences. On the other hand, in habitats No. 2, 3 and 5-8 deer density was regarded as low, based on the habitat selection of red deer (preference for forest) in low-altitude areas in Hungary (Bíró et al., 2006), and also due to separation of habitats No. 6 to 8 from southern red deer populations of Hungary (Szemethy et al., 1996). Habitat-1 was enclosed by the freeway and deer-proof fences, therefore exempt of large game animals. Small mammals (rodents and insectivores) as well as birds are ubiquitous in all habitats, not restricted in their movements by freeway fences.

\section{DNA extraction}

DNA was extracted individually from 264 females of $I$. ricinus, i.e. using up to 20 ticks from each collection in April and May, from each habitat except for habitat-3 (with low abundance of I. ricinus), habitat-6 and -7 (where no ticks were found). Ticks were dried and washed sequentially in detergent containing water, tap water and distilled water for approx. 10 seconds, followed by manual mincing with pointed scissors at the bottom of 1.5-ml Eppendorf tubes in $100 \mu 1$ PBS. The DNA was extracted from this suspension with the QIAamp DNA Mini Kit (QIAGEN, Hilden, Germany) according to the manufacturer's instructions, including an overnight digestion (at $56^{\circ} \mathrm{C}$ ) with proteinase- $\mathrm{K}$ in tissue lysis buffer. Extraction controls were used to monitor cross-contamination between samples.

\section{Molecular analyses}

(a) Molecular detection of A. phagocytophilum was performed with a TaqMan real-time PCR that amplifies a $77 \mathrm{bp}$ long fragment of the gene encoding a major surface protein (msp2) (Courtney et al., 2004), with primers ApMSP2f (forward: 5'-ATG GAA GGT AGT GTT GGT TAT GGT ATT-3'), ApMSP2r (reverse: 5'-TTG GTC TTG AAG CGC TCG TA-3') and the probe ApMSP2p (5'-3': 6-FAM-TGG TGC CAG GGT TGA GCT TGA GAT TG-TAMRA). The 
reaction mixture contained $10 \mu \mathrm{l}$ TaqMan Fast Universal Mastermix (Applied Biosystems, Life Technologies, Foster City, CA), $900 \mathrm{nM}$ primers $(10-10 \mu \mathrm{M}$, $2 \times 1.8 \mu \mathrm{l}), 125 \mathrm{nM}$ probe $(10 \mu \mathrm{M}, 0.4 \mu \mathrm{l}), 1 \mu \mathrm{l}$ water and $5 \mu \mathrm{l} \mathrm{DNA}$ in a final volume of $20 \mu \mathrm{l}$. After an initial denaturation and Taq polymerase activation at $95{ }^{\circ} \mathrm{C}$ for $20 \mathrm{sec}, 40$ cycles of denaturation at $95{ }^{\circ} \mathrm{C}$ for $3 \mathrm{sec}$ as well as annealing-extension at $60^{\circ} \mathrm{C}$ for $30 \mathrm{sec}$ followed. Results were considered positive if the threshold cycle $(\mathrm{Ct})$ value was below 39. The detection limit of this PCR is 0.125 ratio (one-eights) of an A. phagocytophilum infected cell (Courtney et al., 2004).

(b) Evaluation of the presence of Borrelia burgdorferi s.l. was done using a TaqMan real-time PCR targeting a portion of the flagellin gene (Leutenegger et al., 1999). Primers were: B.398f (forward: 5'-GGG AAG CAG ATT TGT TTG ACA-3') and B.484r (reverse: 5'-ATA GAG CAA CTT ACA GAC GAA ATT AAT AGA-3'), and the probe B.421p (5'-3': 6-FAM-ATG TGC ATT TGG TTA TAT TGA GCT TGA TCA GCA A-TAMRA). The reaction volume was $25 \mu 1$, containing 12,5 $\mu \mathrm{l}$ Eurogentec qPCR Mastermix, $600 \mathrm{nM}$ primers $(20-20 \mu \mathrm{M}$, $2 \times 0.75 \mu \mathrm{l}), 80 \mathrm{nM}$ probe $(10 \mu \mathrm{M}, 0.2 \mu \mathrm{l}), 5.55 \mu \mathrm{l}$ water and $0,25 \mu \mathrm{l} \mathrm{UNG}$ and $5 \mu \mathrm{l}$ DNA template. Reaction parameters were the following: initial incubation at $48{ }^{\circ} \mathrm{C}$ for $30 \mathrm{~min}$, denaturation and Taq polymerase activation at $95{ }^{\circ} \mathrm{C}$ for $10 \mathrm{~min}$, then 45 cycles of denaturation at $95^{\circ} \mathrm{C}$ for $15 \mathrm{sec}$ as well as annealingextension at $60^{\circ} \mathrm{C}$ for $1 \mathrm{~min}$. The results were interpreted as positive when the $\mathrm{Ct}$ value was below 40 . The analytical sensitivity of the test is 10 copies of a cloned DNA standard (Leutenegger et al., 1999).

(c) The presence of Rickettsia helvetica DNA was evaluated with a specific real-time PCR assay based on a 65-bp fragment of the 23S rRNA gene (Boretti et al., 2009). The system used the primers Rickhelv.147f (forward: 5'TTT GAA GGA GAC ACG GAA CAC A-3'), Rickhelv.211r (reverse: 5'-TCC GGT ACT CAA ATC CTC ACG TA-') and the probe Rickhelv.170p (5'-3': 6FAM-AAC CGT AGC GTA CAC TTA-MGB-NFQ). The real-time PCR mixtures contained $12.5 \mu \mathrm{l}$ of the $2 \times$ quantitative PCR master mix plus low 5carboxy- X-rhodamine (Eurogentec, Seraing, Belgium), final concentrations of $0.9 \mu \mathrm{M}$ of each primer and $0.25 \mu \mathrm{M}$ of the probe, and $2.5 \mu \mathrm{l}$ or $5 \mu \mathrm{l}$ of the template in a total volume of $25 \mu 1$. Reaction conditions included an initial step of $50{ }^{\circ} \mathrm{C}$ for $2 \mathrm{~min}$ and a denaturation step of $95^{\circ} \mathrm{C}$ for $10 \mathrm{~min}$, followed by $45 \mathrm{cy}-$ cles of $95{ }^{\circ} \mathrm{C}$ for $15 \mathrm{~s}$ and $60^{\circ} \mathrm{C}$ for $1 \mathrm{~min}$. The results were interpreted as positive when the $\mathrm{Ct}$ value was below 40 .

All PCR tests were run while including sequence-confirmed positive and non-template negative controls. Negative and extraction controls remained negative in all tests.

\section{Statistical analyses; definition of overall and whole-season prevalence}

Exact confidence intervals (CIs) for the prevalence rates were calculated at the $95 \%$ level. Prevalence and abundance data were analysed by using Fisher's 
exact test. Nomenclature used in the text include 'overall prevalence', meaning the percentage of infected ticks in all evaluated habitats throughout the sampling period; and 'whole-season prevalence', which is the prevalence based on all sampling occasions (encompassing the whole spring tick season) in a certain habitat (the right three columns in Table 1). Spearman rank correlation was used to test the association between the prevalence rates of $A$. phagocytophilum and $B$. burgdorferi s.l. Differences were considered significant when $\mathrm{P}<0.05$.

\section{Results and discussion}

In the study period, 887 ixodid ticks were collected. These included $704 I$. ricinus $(79.4 \%), 51$ Dermacentor reticulatus $(5.7 \%), 78$ D. marginatus $(8.8 \%)$, 35 Haemaphysalis inermis $(3.9 \%)$ and $19 \mathrm{H}$. concinna $(2.1 \%)$. There was no significant difference in the abundance of tick species between the same habitat types (data not shown), except for grasslands/groves, where Dermacentor spp. occurred only on one side of the freeway (Fig. 1: habitat-3/5 vs. habitat-6/7).

Grasslands are the favoured habitats of Dermacentor spp. in Hungary (Hornok and Farkas, 2009). Temperature and humidity were concordant in the two grasslands (habitat-3 and habitat-7) of the present study (data not shown), and Dermacentor spp. are known for their tolerance of a wide range of abiotic factors, including temperature and humidity (Zajac et al., 2016), which therefore most likely did not cause the differences observed between habitat-3 and habitat-7. On the other hand, the availability of host species is known to be a key factor influencing tick distribution (Trout Fryxell et al., 2015). Thus, the presence of Dermacentor spp. in habitat-3 can be explained by the proximity of a hunting area with high density of game animals (cervids and wild boars), medium-sized carnivores (red foxes: Vulpes vulpes), as well as dogs and horses, which are the main reproductive hosts for adults of $D$. reticulatus and D. marginatus (Nosek, 1972). However, the hunting area was separated from habitat-7 by the freeway, and freeway fences prevent large game animals from crossing (Szemethy et al., 1995; Csohány, 2011). Consequently, this alone could have resulted in reduced presence of red deer in habitat-7. Similarly, in other studies the absence of red deer (and domestic ungulates) was suggested to be a limiting factor in the local distribution of Dermacentor sp. ticks (e.g. Liebisch and Rahman, 1976; Hornok et al., 2014a).

Ixodes ricinus is regarded as the most important tick species to feed on humans in Europe (Gray, 1991). Females of this species (unlike males) need to quest for a host, and (as adults) are the most likely to harbour transstadially transmitted pathogens (Overzier et al., 2013), such as A. phagocytophilum and $B$. burgdorferi s.1.. In addition, females are the most relevant to be evaluated for transovarially transmitted agents, as exemplified by $R$. helvetica. Therefore, in the present study, I. ricinus females collected in five biotopes (forest and grove) 


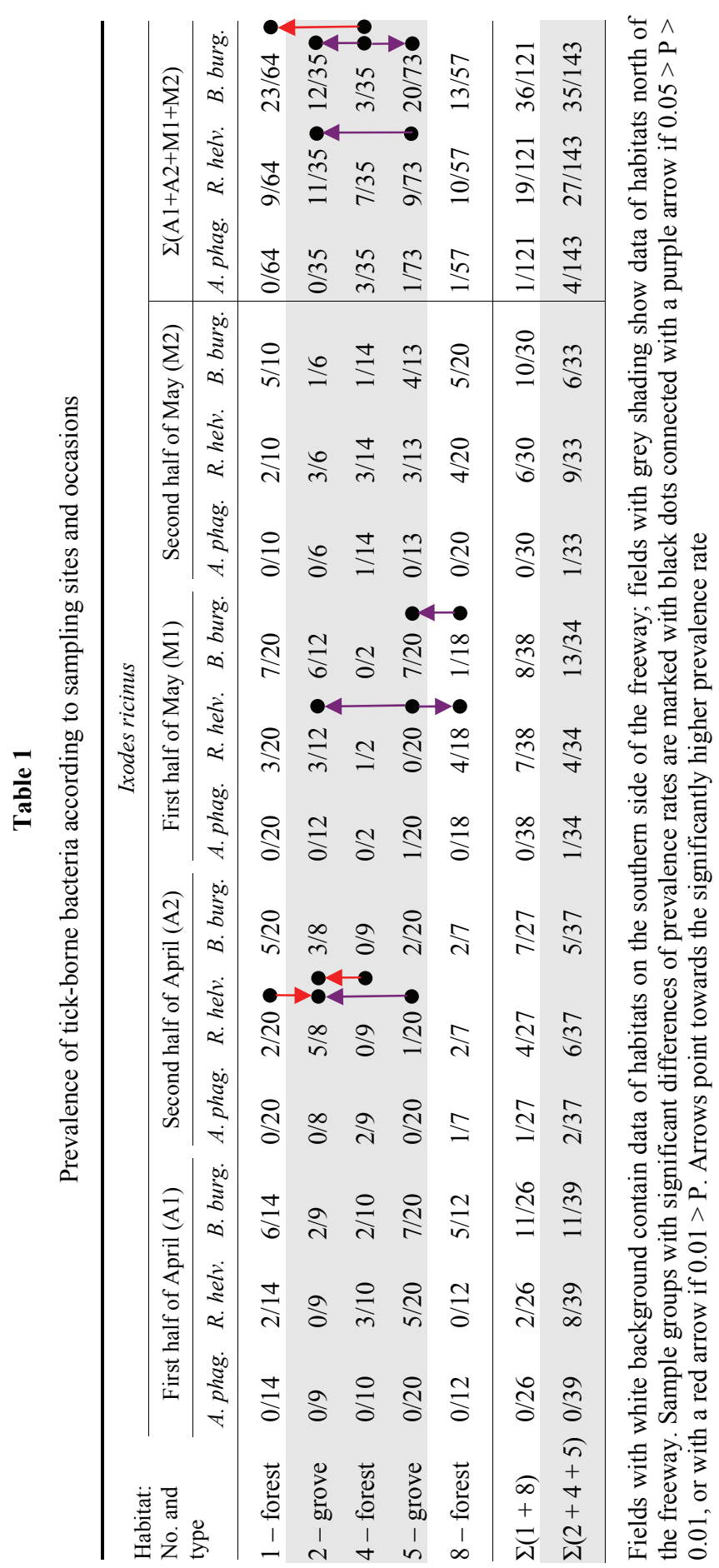


were chosen for molecular screening of tick-borne bacteria. The results of molecular analyses are summarised in Table 1.

In $I$. ricinus females, the overall prevalence of $A$. phagocytophilum was $1.9 \%$ ( 5 out of 264, CI: $0.6-4.4 \%$ ). The highest whole-season prevalence of $A$. phagocytophilum, i.e. $8.6 \%$ ( 3 out of 35 , CI: $1.8-23.1 \%$ ) was found in the hunting area (habitat-4). This is most likely associated with the high density of cervids and wild boars, which are important reservoirs of this bacterium (Stuen et al., 2013). On the other hand, no A. phagocytophilum PCR positive ticks were found in habitats No. 2 and 1 (Table 1), which have either reduced deer density compared to habitat-4, or a complete absence of deer, respectively (Fig. 1: habitat-2 is approx. $4 \mathrm{~km}$ from habitat-4, and habitat-1 is enclosed). Taken together, in rural biotopes evaluated here the prevalence of $A$. phagocytophilum (1.9\%) was significantly $(\mathrm{P}=0.0005)$ lower than in urban biotopes situated approx. $40 \mathrm{~km}$ away (8.8\%: Hornok et al., 2014a), and (in part due to this low rate) did not show significant difference between the two sides of the freeway.

The overall prevalence of $R$. helvetica was $17.4 \%$ (46 out of $264, \mathrm{CI}$ : $13.1-22.6 \%)$. The highest whole-season prevalence of $R$. helvetica in I. ricinus females amounted to $31.4 \%$ (11 out of $35, \mathrm{CI}=16.9-49.3 \%$ ) in habitat-2. Whole-season prevalence rates were significantly different between two distant habitats along the same side of the freeway (habitat-5: 12.3\% [9 out of 73, CI: 5.8-22.1\%] vs. habitat-2: $31.4 \%$ [11 out of 35, CI: $16.9-49.3 \%]$ ), but not between habitats on the opposite sides of the freeway. However, concerning two individual sampling occasions, the prevalence of $R$. helvetica was significantly different between habitats at larger distance $(4 \mathrm{~km})$ from each other (habitat-2 vs. habitat-4/5) and also between habitats close to each other, but on different sides of the freeway (habitat-1 vs. habitat-2; habitat 5 vs. habitat-8) (Table 1). In summary, the prevalence of $R$. helvetica did not correlate with either high or low density of large game animals. This can be explained by the reservoir role of $I$. ricinus ticks (which were ubiquitous in most habitats), as well as by the transovarial maintenance of $R$. helvetica in nature even in the absence of vertebrate hosts (Sprong et al., 2009).

The overall prevalence of $B$. burgdorferi s.1. was $26.9 \%$ ( 71 out of 264 , CI: 21.6-32.7\%). The highest whole-season prevalence of B. burgdorferi s.l., i.e. $35.9 \%$ ( 23 out of 64 , CI: $24.3-48.9 \%$ ) was found in habitat-1, which is a forested resting area enclosed by the freeway on one side and a fence on the other side, thus void of deer (Fig. 1). On the other hand, the lowest whole-season prevalence of B. burgdorferi s.1., i.e. 8.6\% (3 out of 35, CI: $1.8-23.1 \%$ ) was demonstrated in habitat-4, in the forested hunting area. In addition, concerning all evaluated habitats, whole-season prevalence rates of the Lyme disease agent were significantly inversely proportional to the prevalence rates of $A$. phagocytophilum (Spearman's rank correlation: $\mathrm{r}=-0.97, \mathrm{P}=0.005$ ). These findings are most likely related to deer population densities in relevant habitats. As known from data of the 
literature, absence of deer in small areas (under 2.5 Ha, as in habitat-1) will increase the chances that ticks feed on rodents (Perkins et al., 2006), which are the main reservoirs of $B$. burgdorferi s.1.. This in turn will lead to enhanced pathogen prevalence in such small enclosures (so-called 'tick-borne disease hotspots': Perkins et al., 2006), as demonstrated for the forested freeway resting place in the present study. The effect may be the opposite in larger areas with high deer density (as exemplified by habitat-4), where a significant portion of immature ticks may feed on cervids that are incompetent reservoirs of borreliae.

In the entire sampling period, $B$. burgdorferi s.l. showed significantly different whole-season prevalence rates between habitats both on the same and on the opposite sides of the freeway, with a higher level of significance in the latter case (Table 1).

In conclusion, the occurrence of Dermacentor spp. appeared to be confined to one side of the freeway in its vicinity. No significant differences were found in the whole-season prevalence rates of I. ricinus-borne bacteria between similar habitats that were close to each other but separated by the freeway, suggesting the absence of a 'dramatic effect' of these man-made barriers. This is most likely due to the 'buffering effect' of small mammals and birds (which may act as reservoirs of I. ricinus-borne bacteria: Sprong et al., 2009; Hornok et al., $2014 b$ ) that are not prevented from crossing the freeway. However, on individual sampling occasions (which are the closest estimates of risks associated with reallife contact/encounters with ticks), significant differences between prevalence rates of I. ricinus-borne pathogens were observed either between distant habitats, or between close habitats separated by the freeway. In addition, for habitatrelated differences observed in the whole-season prevalence of B. burgdorferi s.l., the level of significance was higher if relevant habitats were also separated by the freeway. These findings exemplify that a fenced freeway may contribute to differences in tick species diversity and local tick-borne pathogen prevalence rates, and this effect is most likely a consequence of its barrier role preventing movements of large game animals (mainly red deer). Furthermore, because freeway fences surround forested resting areas, these may act as deer exclosures, with consequently higher prevalence of Borrelia burgdorferi s.l. (as shown here) and thus higher risks for Lyme disease exposure for humans and pet dogs walking there.

\section{Acknowledgements}

The study was financed by the Hungarian Scientific Research Fund (OTKA grant no. 115854). Miklós Gyuranecz and Kinga M. Sulyok were supported by the Lendület (Momentum) programme (LP2012-22) of the Hungarian Academy of Sciences. This research was supported by the 11475-4/2016/FEKUT grant of the Hungarian Ministry of Human Resources. 


\section{References}

Babos, S. (1965): Kullancsok - Ixodidea [in Hungarian]. Fauna Hungariae 18, 1-38.

Bíró, Z., Szemethy, L., Katona, K., Heltai, M. and Pető, Z. (2006): Seasonal distribution of red deer (Cervus elaphus) in a forest-agriculture habitat in Hungary. Mammalia 70, 70-75.

Boretti, F. S., Perreten, A., Meli, M. L., Cattori, V., Willi, B., Wengi, N., Hornok, S., Honegger, H., Hegglin, D., Woelfel, R., Reusch, C. E., Lutz, H. and Hofmann-Lehmann, R. (2009): Molecular investigations of Rickettsia helvetica infection in dogs, foxes, humans, and Ixodes ticks. Appl. Environ. Microbiol. 75, 3230-3237.

Courtney, J. W., Kostelnik, L. M., Zeidner, N. S. and Massung, R. F. (2004): Multiplex real-time PCR for detection of Anaplasma phagocytophilum and Borrelia burgdorferi. J. Clin. Microbiol. 42, 3164-3168.

Csohány, D. (2011): Sustainability report. Issued by the State Motorway Management Company Ltd. (http://kozadat.nemzetiutdij.hu/, accessed October 11, 2016)

Fajs, L., Durmiši, E., Knap, N., Strle, F. and Avšič-Županc, T. (2012): Phylogeographic characterization of tick-borne encephalitis virus from patients, rodents and ticks in Slovenia. PLoS ONE 7, e48420.

Gray, J. S. (1991): The development and seasonal activity of the tick Ixodes ricinus: a vector of Lyme borreliosis. Rev. Med. Vet. Entomol. 79, 323-333.

Hornok, S. (2009): Allochronic seasonal peak activities of Dermacentor and Haemaphysalis spp. under continental climate in Hungary. Vet. Parasitol. 163, 366-369.

Hornok, S. and Farkas, R. (2009): Influence of biotope on the distribution and peak activity of questing ixodid ticks in Hungary. Med. Vet. Entomol. 23, 41-46.

Hornok, S., Meli, M. L., Gönczi, E., Halász, E., Takács, N., Farkas, R. and Hofmann-Lehmann, R. (2014a): Occurrence of ticks and prevalence of Anaplasma phagocytophilum and Borrelia burgdorferi s.l. in three types of urban biotopes: forests, parks and cemeteries. Ticks Tick Borne Dis. 5, 785-789.

Hornok, S., Kováts, D., Csörgö, T., Meli, M. L., Gönczi, E., Hadnagy, Z., Takács, N., Farkas, R. and Hofmann-Lehmann, R. (2014b): Birds as potential reservoirs of tick-borne pathogens: first evidence of bacteraemia with Rickettsia helvetica. Parasit. Vectors 7, 128.

Jerina, K. (2012): Roads and supplemental feeding affect home-range size of Slovenian red deer more than natural factors. J. Mammal. 93, 1139-1148.

Leutenegger, C. M., Pusterla, N., Mislin, C. N., Weber, R. and Lutz, H. (1999): Molecular evidence of coinfection of ticks with Borrelia burgdorferi sensu lato and the human granulocytic ehrlichiosis agent in Switzerland. J. Clin. Microbiol. 37, 3390-3391.

Levi, T., Kilpatrick, A. M., Mangel, M. and Wilmers, C. C. (2012): Deer, predators, and the emergence of Lyme disease. Proc. Natl. Acad. Sci. U S A 109, 10942-10947.

Liebisch, A. and Rahman, M. S. (1976): Prevalence of the ticks Dermacentor marginatus (Sulzer, 1776) and Dermacentor reticulatus (Fabricius, 1794) and their importance as vectors of diseases in Germany [in German]. Tropenmed. Parasitol. 27, 393-404.

Ng, S., Dole, J., Sauvajot, R., Riley, S. and Valone, T. (2004): Use of highway undercrossings by wildlife in Southern California. Biol. Conserv. 115, 499-507.

Nosek, J. (1972): The ecology and public health importance of Dermacentor marginatus and D. reticulatus ticks in Central Europe. Fol. Parasitol. 19, 93-102.

Overzier, E., Pfister, K., Thiel, C., Herb, I., Mahling, M. and Silaghi, C. (2013): Anaplasma phagocytophilum in questing Ixodes ricinus ticks: comparison of prevalences and partial $16 \mathrm{~S}$ rRNA gene variants in urban, pasture, and natural habitats. Appl. Environ. Microbiol. 79, 1730-1734.

Perkins, S. E., Cattadori, I. M., Tagliapietra, V., Rizzoli, A. P. and Hudson, P. J. (2006): Localized deer absence leads to tick amplification. Ecology 87, 1981-1986. 
Spellerberg, I. F. (1998): Ecological effects of roads and traffic: A literature review. Global Ecol. Biogeogr. 7, 317-333.

Sprong, H., Wielinga, P. R., Fonville, M., Reusken, C., Brandenburg, A. H., Borgsteede, F., Gaasenbeek, C. and van der Giessen, J. W. (2009): Ixodes ricinus ticks are reservoir hosts for Rickettsia helvetica and potentially carry flea-borne Rickettsia species. Parasit. Vectors $2,41$.

Stuen, S., Pettersen, K. S., Granquist, E. G., Bergström, K., Bown, K. J. and Birtles, R. J. (2013): Anaplasma phagocytophilum variants in sympatric red deer (Cervus elaphus) and sheep in southern Norway. Ticks Tick Borne Dis. 4, 197-201.

Szemethy, L., Ritter, D., Heltai, M. and Petö, Z. (1995): The effects of human disturbances on the movements of red deer. In: Proceedings of the XXII. Congress of International Union of Game Biologists, Sofia, Bulgaria. pp. 174-177.

Szemethy, L., Ritter, D., Heltai, M. and Pető, Z. (1996): Spatiotemporal distribution of red deer in hill and plain habitats [in Hungarian]. Vadbiológia 5, 43-59.

Trout Fryxell, R. T., Moore, J. E., Collins, M. D., Kwon, Y., Jean-Philippe, S. R., Schaeffer, S. M., Odoi, A., Kennedy, M. and Houston, A. E. (2015): Habitat and vegetation variables are not enough when predicting tick populations in the southeastern United States. PLoS One 10, $\mathrm{e} 0144092$.

Zając, Z., Katarzyna, B. and Buczek, A. (2016): Factors influencing the distribution and activity of Dermacentor reticulatus (F.) ticks in an anthropopressure-unaffected area in centraleastern Poland. Ann. Agric. Environ. Med. 23, 270-275. 